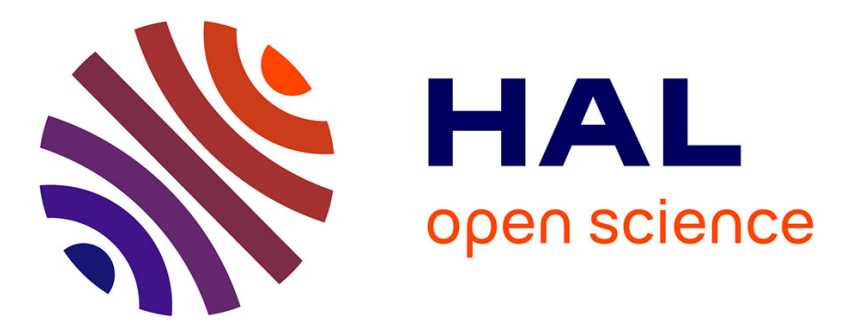

\title{
Self-awareness in Transient Global Amnesia: distinguishing the effects of transient memory disorder vs. pre-existing vulnerability factors
}

Céline Becquet, Fausto Viader, Francis Eustache, Peggy Quinette

\section{- To cite this version:}

Céline Becquet, Fausto Viader, Francis Eustache, Peggy Quinette. Self-awareness in Transient Global Amnesia: distinguishing the effects of transient memory disorder vs. pre-existing vulnerability factors. Neurocase, 2021, 27 (2), pp.196 - 204. 10.1080/13554794.2021.1912359 . hal-03443749

HAL Id: hal-03443749

https://hal-normandie-univ.archives-ouvertes.fr/hal-03443749

Submitted on 23 Nov 2021

HAL is a multi-disciplinary open access archive for the deposit and dissemination of scientific research documents, whether they are published or not. The documents may come from teaching and research institutions in France or abroad, or from public or private research centers.
L'archive ouverte pluridisciplinaire $\mathbf{H A L}$, est destinée au dépôt et à la diffusion de documents scientifiques de niveau recherche, publiés ou non, émanant des établissements d'enseignement et de recherche français ou étrangers, des laboratoires publics ou privés. 


\title{
Self-awareness in Transient Global Amnesia: Distinguishing the effects of transient memory disorder vs. pre-existing vulnerability factors
}

\author{
Céline Becquet ${ }^{\mathrm{a}}$, Fausto Viader ${ }^{\mathrm{a}}$, Francis Eustache ${ }^{\mathrm{a}}$ and Peggy Quinette ${ }^{\mathrm{a} *}$ \\ a“Neuropsychology and Imaging of Human Memory" research unit, Caen-Normandy \\ University-PSL Research University-EPHE-INSERM-Caen University Hospital, Caen, \\ France
}

Neuropsychology and Imaging of Human Memory" research unit

INSERM-EPHE-UNICAEN U1077 - Neuropsychologie et imagerie de la mémoire humaine (NIMH)

Pôle des Formations et de Recherche en Santé (PFRS)

2 , rue des Rochambelles

F-14032 Caen Cedex CS 14032, France

Tel : +33(0)2 31568377 - Fax : +33(0)2 31568391

Céline Becquet : celine.becquet@unicaen.fr

Fausto Viader: fausto.viader@unicaen.fr

Francis Eustache : francis.eustache@unicaen.fr

Peggy Quinette (*corresponding author): peggy.quinette@unicaen.fr 


\section{Abstract}

Numerous evidences suggest the existence of relationships between the impairment of episodic memory, acute stress exposure and variations in self-awareness (SA). Here, we examined 27 patients presenting transient global amnesia (TGA), a clinical condition which combines episodic amnesia and high anxiety, thanks to state and trait questionnaires of SA. We observed variation of SA-state depending on the stage of TGA (acute, recovery and followup). We also found preexisting differences in patient's awareness of their own image when the precipitating event was physical, encouraging us to give more consideration to the social determinants of stress in physiological cascade of TGA.

Keywords: transient global amnesia; objective self-awareness; self-focused attention; episodic memory; anxiety; hippocampus

\section{Introduction}

Transient global amnesia (TGA) is a neurological syndrome characterized by a transient and massive loss of memory with iterative questioning (Hodges \& Warlow, 1990). During the acute phase, patients present memory dysfunction affecting both its anterograde side, particularly impressive because of iterative questioning, and, to a lesser extent, its retrograde side (Guillery-Girard et al., 2004 Viader et al., 2019). The disorder affects exclusively the episodic memory system, making TGA a unique model for the study of its functioning. Because of its transient character and the absence of cognitive reorganization and/or compensatory mechanisms in patients, it is especially adapted to the investigation of cognitive components 
related to episodic memory, such as self-awareness (SA), a high-level function allowing individuals to integrate themselves into experiences they are living and adopt a reflexive position about themselves. Self-awareness is strongly integrated into the episodic memory concept defined by Tulving (1985) which described a first-person memory processed with an inner feeling of reliving or projecting him/her self toward subjective time. Then, the ability to process information orientated toward the self can be consider as involved in the feeling that events belong to the self peculiar to the episodic memory functioning.

SA is a polysemic concept which refers to multiple processes. The objective SA theory defines objective SA as a particular state in which "the person takes himself to be an object" (Duval \& Wicklund, 1972; Wicklund, 1975). According to these authors, attention is a dichotomic function that may be selectively oriented either on the self or on the environment. Objective SA can thus be described as a process in which the focus of attention is oriented towards the self. According functional imaging studies, the process of information related to the self is assumed by the default mode network (DMN), involving medial prefrontal cortices, posterior cingulate cortex, precuneus and lateral parietal cortex, that is deactivated when the attention is engaged toward an external task, at the opposite of the central executive network implicated when the individual is focused on the outside world (Raichle, 2015).

In TGA, a study exploring metacognition, a high-level process requesting objective SA, showed that patients had poor explicit knowledge of their amnesia during the acute stage (Hainselin et al., 2012). This study also showed that these difficulties appeared concomitantly with a state of high anxiety, characteristic in acute TGA patients (Noël et al., 2008). TGA often takes place around precipitating events. These events can be physical (swimming in cold water, sexual intercourse, intensive gardening...), psychological (bad news disclosure...) or both (a medical test can both be painful and psychologically dreaded by the patient). According to Bartsch et al (2010), such precipitating events result in a physiological stress, that in turn 
triggers a cascade of metabolic reactions, finally giving rise to a temporary dysfunction of the CA1 hippocampal neurons, that are especially vulnerable to metabolic stress (Bartsch et al., 2006). In other pathological conditions linked to stress reactions, such as post-traumatic stress disorder (PTSD) or situational depression, modifications of self-focused attention, generally evidenced by questionnaires, have sometimes been observed (for review: Ingram, 1990), as well as impaired episodic memory (Dere et al., 2010). Nevertheless, while the relationships between self-focused attention and negative affect or between stress and memory have been thoroughly investigated, the way by which SA interacts with memory has not been studied so far in amnesic patients (Mor \& Winquist, 2002).

Self-focused attention can depend on pre-existing personal characteristics, that could influence vulnerabilities to develop pathological stress reactions (Ingram, 1990). The presence of psychogenic vulnerabilities in TGA patients has been suggested. Inzitari et al. (1997) observed phobic attitudes in about half of the 51 patients evaluated in their study. In a retrospective study including 142 cases, Quinette et al., (2006) also found phobic attitudes, and showed that $21.2 \%$ of TGA patients had a medical history of depression or anxiety episodes. In Döhring et al., (2014), acute TGA patients used less effective coping strategies than did control subjects, with a tendency to focus on internal process (emotion-centered coping), which is often considered as less adaptive. This study, including 21 acute TGA patients, failed to find association between stressful events, hippocampal CA1 lesions and behavioral patterns during the TGA attack, but led the authors to identify a subcategory of "emotional" TGA patients that could affect some predisposed people. This idea was already evoked by Quinette et al. (2006) who distinguished with a hierarchical cluster analysis, three categories of TGA patients: 1) a first category associating emotional variables and the psychopathological variables with women patients; 2) a second category associating men with an absence of medical history and physical 
precipitating events; 3 ) a third category gathered a medical history of migraine and the younger patients.

The present study focused on two considerations: 1) the relationship between selffocused attention (objective SA) and episodic memory functioning during the acute phase of TGA; 2) the pre-existing disposition in TGA patients to be self-focused.

In the first part of this study, we focused on situational effect of episodic memory dysfunction on SA by comparing patients seen during the acute phase of TGA to those during the recovery phase or follow-up. In the second part, we considered pre-existing characteristics of SA in patients according to the kind of precipitating event at the origin of the TGA episode (psychological, physical, and other or none). The objective was to learn if pre-existing SA tendencies might predict the kind of precipitating event related to TGA. Thus, we compared scores in trait-SA in patients seen during periacute stages compared to follow-up patients according to their different precipitating event groups, to better understand interactions between situational and pre-existing dimensions.

\section{Materials and methods}

\section{Population}

Data of 27 patients presenting or who had experienced TGA were collected during their admission to the emergency or the neurological departments of Caen University Hospital between 2016 and 2019. All the patients met the clinical diagnostic criteria for TGA (Hodges \& Warlow, 1990) and had normal neurological and brain CT scan examinations. The study was approved by the local ethics committee of the medical faculty of Caen university and conformed 
to the Declaration of Helsinki. All participants were informed and gave their consent to take part to the research.

To assess episodic memory functioning, we used a verbal episodic memory task, the ESR-r (encoding, storage, retrieval) (Eustache et al, 2015). We used the strategic-learning part of this task consisting in a verbal learning of a list of words involving a semantic processing of the information by asking the participants to formulate a sentence with the target word (ie. “turnip"?”). A cued-recall was proposed every other item to make sure that deep encoding had been done (Craik \& Tulving, 1975). Three indicators were calculated: the encoding score (on 16), the immediate free recall score (on 16) and the delayed 20 minutes recognition score (on 16).

Patients seen within the first 24 hours of the episode formed the "acute" and the "recovery" groups. Those who had impaired anterograde memory at the 20 min recognition score of the ESR test (z-score inferior to -1.65 in comparison to the normative values in Eustache et al., 2015) were classified into the acute group, and those presenting no anterograde memory impairment into the recovery group (see table in Appendix for complete description of patients). Patients seen within the first $24 \mathrm{~h}$ but for whom these data were missing were classified into the acute group if they had iterative questioning and into the recovery group if not.

Six patients were seen during the acute phase, 8 during recovery and the remaining 13 at a follow-up appointment between 1 and 15 months (mean=3.88; $\mathrm{SD}=3.88$ ) after the episode. Mean TGA duration was 2 hours and 40 minutes ( $\mathrm{SD}=2$ hours and 09 minutes). In the second part of the study, we further classified the patients according to the kind of precipitating events potentially linked to the occurrence of the TGA. This classification of events (from 1 to 8 ) is inspired from (Quinette et al., 2006): 1=emotional stress the day of the episode; $2=$ physical 
effort the day of the episode; $3=$ severe pain; $4=$ unusual contact with water; $5=$ sexual intercourse; $6=$ other; $7=$ context of stress during the weeks preceding the episode; $8=$ no identified precipitating event. Three groups of patients were defined as follows: PSY= TGA following to psychological events (events 1 and 7); PHYS=physical event having occurred in the $24 \mathrm{~h}$ before the episode (events 2,3,4 and 5); NONE=no or other precipitating event $(6,8)$ (see further information about precipitating events in table in Appendix). When several events seemed to be present at the same time, e.g. for PA_02 who had a sea bath the day of the TGA (4), while she was confronted to a context of stress (7), we chose the event closer to the episode (in this case, the sea bath, so we classified this patient into the PHYS group). Patients were compared with 11 normal-control (NC) subjects matched for age and education level.

\section{Assessments}

\section{Situational self-awareness}

The French version of the Situational Self-Awareness Scale (SASS) (Govern \& Marsch, 2001) traduced by Auzoult (2013) was used to assess subjective levels of patients' immediate SA. For each of the 9 items, patients had to respond on a 5-point Lickert scale ranging from 1 (strongly disagree) to 5 (strongly agree). Three different scores were calculated and expressed in mean: private SA, public SA and surroundings (Auzoult, 2013). Private SA corresponds to the awareness of personal feelings, thought or actual state ("Right now, I am conscious of my inner feelings"), while public SA corresponds to the attention of the subject of his/her own image reflected toward other people ("Right now, I am concerned about what other people think of me"). Both of these two scales concern personal SA. On the other hand, the surroundings scale concerns the attention of the subject dedicated toward the external world ("Right now, I am conscious of what is going on around me"). 


\section{Dispositional self-awareness}

We used the French version of the Self-Consciousness Scale (SCS) (Fenigstein et al, 1975) traduced by Rimé \& Le Bon (1984) to assess the dispositional or trait SA on three scales (private SA: eg. "I'm always trying to figure myself out", public SA: eg. "I'm usually aware of my appearance", social anxiety: eg. "I get embarrassed very easily"). For each of the 23 propositions supposed to describe themselves, participants have to pick on a 5-point scale between: $0=$ false, $1=$ more or less false, $2=I$ don't know, $3=$ more or less true, $4=$ true. Scores were expressed in mean of propositions for each of the three scales.

\section{Anxiety}

In order to assess anxiety, we used the Spielbergers' State-trait anxiety inventory (STAI). Both scales (state and trait) were proposed to patients at the same time.

\section{Statistical methodology}

We used non-parametric tests. Group comparisons were processed with Kruskal-Wallis ANOVAs by Ranks (H test). Post-hoc tests were realized with Mann \& Whitney U tests. Intragroup comparisons were processed with Friedman ANOVAs test and intra-group post-hoc analyses were performed with Wilcoxon matched pair tests. Effect sizes were expressed in Spearman's $r$ coefficient of concordance. 


\section{Results}

\section{Part 1: Self-awareness and episodic memory at different stages of TGA}

In this part, we explored the relationship between episodic memory dysfunction and situational self-awareness ("TGA stage" factor) (Table 1). We measured trait SA to control for a possible bias linked to intrapersonal characteristic.

\section{[Table 1 near here]}

Patients in acute phase obtained lower scores than patients in recovery group in every part of the ESR-r (all $p<.01$, all $r>0.82$ ), same compared to follow-up and NC groups (all $p<.001$, all $r>0.77$ ) (Fig.1.).Patients in recovery phase were not different than follow-up and NC groups for the encoding and the 20' recognition scores (all $p>0.79$ ) but tended to obtain lower score than follow-up patients (Mann \& Whitneys'U test $=10.5, p<.05, \mathrm{r}=0.57$ ) and NC group $(p=0.08)$ for the free recall score. Follow-up patients did not differ from NC group in none ESR score (all $p>0.42$ ).

State-anxiety (STAI A) decreased significatively with TGA phase (Kruskal-Wallis' H test $=9.80, p<.05)$ (Table.1). The level of state-anxiety was higher in the acute than in the follow-up (Mann \& Whitneys' U test $=4.5, \mathrm{Z}=2.22, p<.05, \mathrm{r}=0.58$ ) and the $\mathrm{NC}$ groups (Mann $\&$ Whitneys' $\mathrm{U}$ test $=3.5, \mathrm{Z}=2.16, p<.05, \mathrm{r}=0.60$ ). There was no significant difference between the acute and recovery groups $(p=0.14)$. Patients from the recovery group had a higher level of state-anxiety than patients from the follow-up group (Mann \& Whitneys' $U$ test $=12$, $\mathrm{Z}=2.07, p<.05, \mathrm{r}=0.50)$ but did not differ from NC subjects $(p=0.12)$. Patients from the followup group did not differ from NC subjects $(p=0.54)$. Kruskal-Wallis ANOVA did not show group effect for trait-anxiety (STAI B) $(p=0.28)$. 


\section{Self-awareness}

Kruskal-Wallis ANOVA for SASS found no effect of the TGA stage on any scale between patients (all $p>0.31$ ). Friedman's ANOVA showed differences between SASS' subscales in all (all $p<.05$ ) but the acute TGA group (ANOVA $\mathrm{Chi}^{2}=1.37 ; p=0.50$ ). In every group except the acute group (Wilcoxon's $\mathrm{Z}$ test: all $p>0.22$ in the acute group), participants were more focused toward surroundings than toward private and public self-representations (Fig.1).

[Figure 1 near here]

Kruskal-Wallis test did not reveal differences between groups for the self-awareness trait scale (SCS) (all $p>0.07$ ).

\section{Part 2: Personality particularities in TGA according to the precipitating event \\ group}

Here, patients were compared for dispositional self-consciousness or anxiety-trait to the same control group as in part 1 , according to the kind of precipitating event $($ psychological $=$ PSY, physical $=$ PHYS, and absent $=$ NONE) $($ Table 2$)$. As in part.1, we controlled for situational SA between groups to avoid a bias linked to the actual memory status of patients. Afterwards, we clustered patients seen the day of the TGA (acute and recovery patients) into the periacute group to compare with patients seen during follow-up (Table 3.). We excluded the NONE group from these analyses because it includes only 3 patients. Mann \& Whitney analyses were carried out. We compared PSY periacute and PHYS periacute patients, PSY follow-up and PHYS follow-up patients to explore the effect of the precipitating event group in patients seen at the same phase of TGA. We compared PSY periacute and PSY follow-up 
patients, and PHYS periacute and PHYS follow-up patients to explore more specifically the effect of the temporality in each group separately.

None TGA precipitating event group differed from NC subjects in ESR encoding (H Kruskal-Wallis'test $=4.04, p=0.26)$ nor in ESR 20' recognition $(\mathrm{H}$ Kruskal-Wallis'test $=4.85$, $p=0.18$ ) (Fig.2.). Nevertheless, there is an effect of the group for ESR free recall (H KruskalWallis'test $=8.57, p<0.05)$. TGA patients from PSY group get lower scores than PHYS group (Mann-Whitney s' $\mathrm{U}$ test $=39, \mathrm{Z}=-2.09, p<.05, \mathrm{r}=0.42$ ) and NC group (Mann-Whitney s'U test= 28.5, $\mathrm{Z}=-2.67, p<.01, \mathrm{r}=0.53)$.

Anxiety trait (Stai_B) was comparable for patients of any groups and with healthy subjects $(\mathrm{H}=0.47, p=0.93)$. Same, state anxiety (Stai_A) did not differ significantly between none group $(\mathrm{H}=2.32, p=0.51)$.

\section{[Table 2 near here]}

\section{[Table 3 near here]}

Of our 27 patients, 10 had a history of depression or anxiety. Another one, PA_13, did not report depression or anxiety history but she evoked several major psychic traumas. PA_27 did not report anxiety disorders. Nevertheless, she followed class against aquaphobia. TGA occurred during one of these sessions of aquaphobia class. Pearson's Chi-square tests did not reveal any dependency in TGA patients between the precipitating event group (PSY versus PHYS $)$ and the presence of psychiatric medical history $\left(\mathrm{Chi}^{2}=1.60 ; \mathrm{df}=1 ; p=0.21\right)$ nor between the gender and the kind of precipitating event $\left(\mathrm{Chi}^{2}=0.18 ; \mathrm{df}=1 ; p=0.67\right)$.

\section{Self-awareness}

There was no significant group effect in Self-Consciousness scale (SCS) for "private self-awareness" $(\mathrm{H}=5.68, p=0.13)$ and "social anxiety" $(\mathrm{H}=3.36, p=0.34)$ scores (Fig.2), with 
only a trend for "public self-awareness" score $(\mathrm{H}=7.58, p=0.06)$. Mann \& Whitney test showed that patients from PHYS group reported higher public self-awareness than patients from PSY group $(\mathrm{U}=28.5, \mathrm{Z}=2.28, p<.05, \mathrm{r}=0.48)$ an $\mathrm{NC}$ subjects $(\mathrm{U}=30.5, \mathrm{Z}=1.94, p<.05, \mathrm{r}=0.41)$.

\section{[Figure 2 near here]}

Friedman ANOVAs revealed no difference between the three scales of the SelfConsciousness scale SCS in PSY group (Friedman's Anova $\mathrm{Chi}^{2}=3.5 ; p=0.17$ ), NONE group (Friedman's Anova Chi² $=0.67 ; p=0.72$ ) and NC group (Friedman's Anova $\mathrm{Chi}^{2}=0.97 ; p=0.61$ ). Nevertheless, we found an effect of the scale in the PHYS group (Friedman's Anova $\mathrm{Chi}^{2}=9.45$; $p<.01$ ) with a public SA score superior to the social anxiety score (Wilcoxon's $\mathrm{Z}=2.67 ; p<.01$; $\mathrm{r}=0.57)$ and a trend toward higher public SA score compared to private SA score $(p=0.07)$.

Kruskal-Wallis ANOVA did not show difference between groups in situational selfawareness scale for private $(p=0.28)$ and public $(p=0.29)$ SA. We observed a trend for surrounding scale $(p=0.07)$, but post-hoc tests were not significant (all $p>0.15)$ except between PSY and PHYS groups, with a higher level of surrounding awareness for the PSY group $(\mathrm{U}=39.5, \mathrm{Z}=1.85, p<.05, \mathrm{r}=0.45)$.

Comparison of periacute and follow-up patients in function of their precipitating event group

About situational self-awareness, we found no difference between groups in SASS scores (all $p>0.11)$.

Regarding dispositional self-awareness, as previously observed, we found a difference between PSY and PHYS patients in the "public SA" score of the SCS, in patients seen during the periacute phase (Mann \& Whitney $\mathrm{U}=6.5, p<.05, \mathrm{r}=0.53$ ). We found no such difference for this scale in PHYS patients seen in follow-up compared to PSY follow-up patients $(p=0.17)$, 
nor in other scales (all $p>0.17$ ). There was no difference in any scale for periacute versus follow-up patients in PSY and PHYS groups (all $p>0.47$ ).

\section{Discussion}

In studies of TGA, self-awareness (SA) is usually considered to be preserved during the episode (Frederiks, 1993; Noël et al., 2015; Quinette et al., 2006) except for metacognitive abilities (Hainselin et al., 2012). In these studies, however, the concept of SA is used as to mean the global preservation of semantic personal knowledge, which is independent from episodic memory functioning (Noël et al., 2015; Quinette et al., 2006). Here, we focused on objective SA, exploring the ability to process self-related information as the object of the consciousness (Duval \& Wicklund, 1972).

The present study sought to explore links between objective SA, episodic memory functioning and vulnerability factors in TGA. The first part focused on state dimension by comparing patients seen at different stages of the attack (acute, recovery, follow-up) while the second part explored pre-existing SA dimensions in patients according to the kind of precipitating event of the attack (psychological, physical or none).

\section{Situational dimensions of self-awareness in TGA}

Regarding situational dimension of SA, our results revealed that awareness of surroundings was higher than personal SA (public and private) in all but the acute group, in which awareness was equally distributed between self and surroundings. This result is consistent with another study we led, showing that, in the acute phase, TGA patients tended to use more often first-person pronoun than control subjects when asked to give autobiographical memories, supporting the idea that attention towards the self is increased during the acute phase 
of TGA (Becquet et al, in progress). This excess of attention towards the self in the acute stage of TGA parallels the high level of anxiety-state found in this group. The anxiety caused by the TGA condition, may lead patients to focus on themselves rather than on the environment. That might contribute to the characteristic iterative questioning during TGA: "Where they are, where are their relatives, why they do not remember having been to the grocery" ...etc.

In TGA, poor metacognitive abilities (e.g. SA of cognitive deficits) was already observed, with an impaired awareness of memory disorder during the acute phase (Hainselin et al., 2012) suggesting that an intense self-focused attention could not necessary lead to efficient metacognitive abilities in this population. Numerous studies put in evidence that the episodic memory disorder observed during TGA are related to a transient hippocampus impairment (for a review see: Bartsch \& Deuschl, 2010). Hippocampus structures dysfunction was already involved in SA disturbances in amnesic patients. Chavoix and Insausti (2017) reviewed several functional imaging studies suggesting relationships between anomalies in medial temporal lobes structures, including hippocampus, and disabled metacognitive abilities in patients suffering from neurodegenerative diseases. More specifically, some of these studies put in evidence that the lack of SA in neurodegenerative diseases could be associated to disconnection between cortical midline structures, supporting SA (for review see: Northoff et al, 2006), and hippocampus areas (Perrotin et al., 2015). From an experimental study investigating healthy participants, Bergouignan et al (2014) also put in evidence relationships between modified SA and activity changes in hippocampus leading to memory dysfunction, arguing from a strong relationship between these two processes. Moreover, during the acute phase of TGA, a lack of functional connectivity in executive network, including prefrontal areas, was also recently observed, suggesting that even the episodic memory disorder is the most characteristic feature of TGA, impaired connectivity in prefrontal areas could also be involved in SA modifications, an hypothesis that remain to be explored deeply (Zidda et al., 2019). Another hypothesis that 
could be proposed involves a reduced connectivity into the salience network, especially the fronto-insular connectivity, also reported in TGA patients in Zidda et al (2019). The salience network is known to be involved in switching between the DMN and the central executive network and then from the processing of self information toward external task (Goulden et al, 2014). In that case, the self-focused attention in acute TGA could result from difficulties to switch the locus of attention, which could be related to impairment in prefrontal areas functioning and/or salience network connectivity.

Taken together, these data suggest that SA variations found in TGA could be an effect of the episodic memory dysfunction more than pre-existing dimensions in SA, which did not differ between patients classified according the stage of TGA in the first part of the present study. However, several reports suggested that psychological predisposing factors could be involved in TGA and differ according to the kind of precipitating events linked to the occurring of the attack (Döhring et al., 2014; Quinette et al., 2006). These predisposing factors were explored deeply in the second part of the study.

\section{Predisposing psychological dimensions in TGA}

The physiopathological mechanisms of TGA are only partially known. They are thought to include an acute metabolic stress of hippocampus areas impairing its functioning (Bartsch \& Deuschl, 2010). Since the 90's, it has been hypothesized that, in some cases, TGA could result from a physiological cascade led by emotional arousal or the occurrence of a phobogenic situation (Inzitari et al., 1997; Pantoni et al., 2000). Espiridion et al (2019) recently presented a case-study of a patient who had experienced a TGA in a context of PTSD, a few days after a psychological appointment in which trauma was evoked. An enhanced secretion of cortisol has been found during the acute phase of TGA, correlating with symptoms of depression and anxiety and a persisting hyper-reactivity to an experimental stress (socially evaluated cold 
pressor test (SECPT)) in the recovery phase, again supporting the hypothesis that stress might play a significant part in the pathogenesis of TGA (Griebe et al., 2019; Schneckenburger et al., 2020).

While the amnesic syndrome of TGA is stereotyped, the medical histories of TGA patients are extremely varied. In large cohort studies, Quinette et al (2006) (142 cases) and Bartsch et al (2010), who compiled data from 631 TGA episodes in a review, showed that about $30 \%$ of patients presented TGA following emotional stress while in 30\% TGA was associated to strenuous physical activity. In addition, Quinette et al (2006) and Döhring et al (2014) evoked possible psychopathological vulnerabilities in TGA patients, especially in the emotional or "psychological" category of patients. Many patients from the present study had experienced major traumas (find a suicided father, mortal car accident, repeated abuses, violent decease of a child...) and/or medical history of depression, as has been already reported (Inzitari, et al., 1997; Leonardo Pantoni et al., 2005; Quinette et al., 2006). Nevertheless, we found no relationship between the precipitating event group and the psychiatric history in our patients. This could suggest that the psychological event TGA group is not necessarily composed of psychologically vulnerable people, even if a psychopathological history seems to constitute a general risk factor for all kinds of TGA.

Regarding pre-existing SA dimensions, our results showed a tendency to a high level of public SA in patients from the PHYS group. In this group, TGA followed an intense physical effort (see description of patients in Appendix). In our study, most patients from the physical precipitating event group went over their physical condition by high demand activities such as “strong" gardening, gym, carrying alone a washing machine, etc. TGA episodes may also occur during an overwork period (Fisher, 1982; Quinette et al., 2006). This is often studied in a professional context, but the term overwork is also applicable to "domestic overwork" or “physical overwork", as in some of our patients. Social psychology literature about overwork 
suggests that even if some particular personalities are more likely exposed to develop workaholic behaviors (work investment considered as pathological), these behaviors are most of all closely linked to social demands (Schaufeli, 2016). In this case, high public SA in PHYS TGA patients could be related to an increased understanding of social expectancies, that could lead to workaholic behaviors (in a broader sense including not only the professional sphere) and overwork situations contributing to the genesis of TGA. Further studies should be led in TGA to consider the social context of onset of this event rather than the personality of subjects.

To conclude, in "physical-event" patients, the organism is stressed because it is pushed out of its limits, possibly without the patient being aware of the stress situation. Such patients are more attentive to their public image and possibly to social expectancies, which could lead them to exceed their body limits. "Psychological-event" patients, however, do perceive their stress and it could be the failure of defensive coping strategies that leads to the physiological cascade of TGA (Döhring et al.,2014). These interpretations are consistent with the increased level of state-anxiety reported during the acute TGA (Noel et al., 2008) also found in the present study, and the involvement of hippocampal CA1 lesion on one of the most possible pathogenesis of TGA, this latter region processing both episodic memory and stress-regulation responses (Bartsch et al., 2007; Bartsch \& Deuschl, 2010).

\section{Acknowledgments}

We thank Esther Ivanusa, Antoine Dumas and Cécile Saget for collecting data from the healthy controls, and Julien Cogez, Alice Pélerin and Aurelija Juskenaite for their assistance in recruiting patients. 


\section{Conflicts of Interest: None.}

\section{References}

Auzoult, L. (2013). A French version of the situational self-awareness scale. Revue europeenne de psychologie appliquee, 4-10.

Bartsch, T., Alfke, K., Stingele, R., Rohr, A., Jansen, O., \& Deuschl, G. (2006). Selective affection of hippocampal CA-1 neurons in patients with transient global amnesia without long-term sequelae. Brain, 129, 2874-2884. https://doi.org/10.1093/brain/awl248

Bartsch, T., Alfke, K., Deuschl, G., \& Jansen, O. (2007). Evolution of Hippocampal CA-1 Diffusion Lesions in Transient Global Amnesia. Annals of Neurology, 62, 475-480. https://doi.org/10.1002/ana.21189

Bartsch, T., \& Deuschl, G. (2010). Transient global amnesia: functional anatomy and clinical implications. The Lancet Neurology, 9, 205-214. https://doi.org/10.1016/S14744422(09)70344-8

Chavoix, C., \& Insausti, R. (2017). Self-awareness and the medial temporal lobe in neurodegenerative diseases. Neuroscience and Biobehavioral Reviews, 78, 1-12. https://doi.org/10.1016/j.neubiorev.2017.04.015

Dere, E., Pause, B. M., \& Pietrowsky, R. (2010). Emotion and episodic memory in neuropsychiatric disorders. Behavioural Brain Research, 215(2), 162-171.

https://doi.org/10.1016/j.bbr.2010.03.017

Döhring, J., Schmuck, A., \& Bartsch, T. (2014). Stress-related factors in the emergence of transient global amnesia with hippocampal lesions. Frontiers in behavioral neuroscience, 8, 287. https://doi.org/10.3389/fnbeh.2014.00287

Duval, S., \& Wicklund, R. A. (1972). A theory of objective self-awareness. New York: Academic.

Fenigstein, A., Scheier, M. F., \& Buss, A. H. (1975). Public and private self-consciousness: Assessment and theory. Journal of consulting and clinical psychology, 43(4), 522.

Fisher, C. M. (1982). Transient Global Amnesia Precipitating Activities and Other Observations. Archives of neurology, 39, 605-608.

Frederiks, J. A. (1993). Transient Global Amnesia. Clinical Neurology and Neurosurgery, 95, 265-283. https://doi.org/10.1016/j.ncl.2011.07.004

Goulden, N., Khusnulina, A., Davis, N. J., Bracewell, R. M., Bokde, A. L., McNulty, J. P., \& Mullins, P. G. (2014). The salience network is responsible for switching between the default mode network and the central executive network: replication from DCM. Neuroimage, 99, 180-190.

Govern, J. M., \& Marsch, L. A. (2001). Development and validation of the situational self-awareness scale. Consciousness and cognition, 10(3), 366-378. 
Griebe, M., Ebert, A., Nees, F., Katic, K., Gerber, B., \& Szabo, K. (2019). Enhanced cortisol secretion in acute transient global amnesia. Psychoneuroendocrinology, 99, 72-79. https://doi.org/10.1016/j.psyneuen.2018.08.033

Hainselin, M., Quinette, P., Desgranges, B., Martinaud, O., de La Sayette, V., Hannequin, D., Viader, F., \& Eustache, F. (2012). Awareness of disease state without explicit knowledge of memory failure in transient global amnesia. Cortex, 48(8), 1079-1084.

https://doi.org/10.1016/j.cortex.2012.02.003

Ingram, R. E. (1990). Self-Focused Attention in Clinical Disorders: Review and a Conceptual Model. Psychological bulletin, 107(2), 156-176.

Inzitari, D., Pantoni, L., Lamassa, M., Pracucci, G., Marini, P., \& Pallanti, S. (1997). Emotional arousal and phobia in Transient Global Amnesia. Archives of neurology, 54(7), 866-873.

Mor, N., \& Winquist, J. (2002). Self-focused attention and negative affect: A meta-analysis. Psychological Bulletin, 128(4), 638-662. https://doi.org/10.1037/0033-2909.128.4.638

Noel, A., Quinette, P., Gulllery-Girard, B., Dayan, J., Piolino, P., Marquis, S., ... \& Eustache, F. (2008). Psychopathological factors, memory disorders and transient global amnesia. The British Journal of Psychiatry, 193(2), 145-151. https://doi.org/10.1192/bjp.bp.107.045716

Noël, A., Quinette, P., Hainselin, M., Dayan, J., Viader, F., Desgranges, B., \& Eustache, F. (2015). The Still Enigmatic Syndrome of Transient Global Amnesia: Interactions Between Neurological and Psychopathological Factors. Neuropsychology Review, 25(2), 125-133. https://doi.org/10.1007/s11065-015-9284-y

Pantoni, L., Lamassa, M., \& Inzitari, D. (2000). Transient global amnesia: a review emphasizing pathogenic aspects. Acta neurologica scandinavica, 102(5), 275-283.

Pantoni, L., Bertini, E., Lamassa, M., Pracucci, G., \& Inzitari, D. (2005). Clinical features, risk factors, and prognosis in transient global amnesia: A follow-up study. European Journal of Neurology, 12(5), 350-356. https://doi.org/10.1111/j.1468-1331.2004.00982.x

Perrotin, A., Desgranges, B., Landeau, B., Mézenge, F., La Joie, R., Egret, S., .. \& Chételat, G. (2015). Anosognosia in Alzheimer Disease: Disconnection between Memory and Self-related Brain Networks. Annals of Neurology, 78(3), 477-486. https://doi.org/10.1002/ana.24462

Quinette, P., Guillery-Girard, B., Dayan, J., Sayette, V. D. L., Marquis, S., Viader, F., ... \& Eustache, F. (2006). What does transient global amnesia really mean? Review of the literature and thorough study of 142 cases. Brain, 129(7), 1640-1658. https://doi.org/10.1093/brain/awl105

Raichle, M.E. (2015). The Brain's Default Mode Network. Annual review of neuroscience, 38, 433-447. https://doi.org/10.1146/annurev-neuro-071013-014030

Rimé, B., \& Le Bon, C. (1984). Le concept de conscience de soi et ses opérationnalisations. L'année psychologique, 84(4), 535-553. https://doi.org/10.3406/psy.1984.29051

Schaufeli, W. B. (2016). Heavy work investment, personality and organizational climate. Journal of Managerial Psychology, 31(6), 1057-1073. https://doi.org/10.1108/JMP-07-2015-0259 
Schneckenburger, R., Hainselin, M., Viader, F., \& Eustache, F. (2020). Serum cortisol levels in patients with a transient global amnesia. Revue Neurologique, 9-12. https://doi.org/10.1016/j.neurol.2019.08.011

Tulving, E. (1985). Memory and Consciousness. Canadian Psychology, 26, 1-12.

Viader, F., Quinette, P., \& Cogez, J. (2019). Transient global amnesia. Journal Europeen des Urgences et de Reanimation, 31(1), 42-49. https://doi.org/10.1016/j.jeurea.2018.11.002

Wicklund, R. A. (1975). Objective self-awareness. In Advances in experimental social psychology (Vol. 8, pp. 233-275). Academic Press.

Zidda, F., Griebe, M., Ebert, A., Ruttorf, M., Roßmanith, C., Gass, A., ... \& Szabo, K. (2019). Resting-state connectivity alterations during transient global amnesia. NeuroImage: Clinical, 23, 101869. https://doi.org/10.1016/j.nicl.2019.10186

Northoff, G., Heinzel, A., de Greck, M., Bermpohl, F., Dobrowolny, H., \& Panksepp, J. (2006). Selfreferential processing in our brain-A meta-analysis of imaging studies on the self. NeuroImage, 31(1), 440-457. https://doi.org/10.1016/j.neuroimage.2005.12.002

Bergouignan, L., Nyberg, L., \& Ehrsson, H. H. (2014). Out-of-body-induced hippocampal amnesia. PNAS, 111(12), 4421-4426. https://doi.org/10.1073/pnas.1318801111

Auzoult, L. (2013). A French version of the situational self-awareness scale. Revue Européenne de Psychologie Appliquée/European Review of Applied Psychology, 63(1), 41-47. http://doi.org/10.1016/j.erap.2012.08.004

Bartsch, T., \& Deuschl, G. (2010). Transient global amnesia: functional anatomy and clinical implications. The Lancet Neurology, 9(2), 205-214. 


\section{Appendix. Presentation of patients participating to this study.}

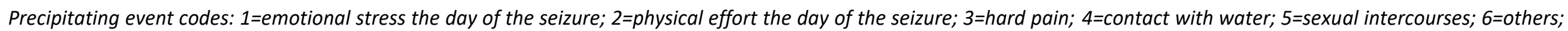
$7=e x t e n d e d$ context of stress during the weeks preceding the seizure; 8=no identified precipitating event.

\begin{tabular}{|c|c|c|c|c|c|c|c|}
\hline & PA_01 & PA_02 & PA_03 & PA_04 & PA_06 & PA_07 & PA_08 \\
\hline & acute & acute & acute & acute & acute & recovery & recovery \\
\hline gender & $\mathrm{F}$ & $\mathrm{F}$ & $\mathrm{F}$ & $\mathrm{F}$ & $\mathrm{F}$ & $\mathrm{M}$ & $\mathrm{M}$ \\
\hline age & 75 & 48 & 62 & 68 & 67 & 67 & 49 \\
\hline level of education & 9 & 17 & 15 & 8 & 11 & 15 & 11 \\
\hline Memory score (z-score)* & -17.05 & -22.5 & -33.76 & -7.05 & -24.71 & 0.29 & 0.28 \\
\hline number of TGA & 1 & 1 & 1 & 1 & 1 & 1 & 1 \\
\hline psychiatric history & $\begin{array}{l}\text { anxious disorders in } \\
\text { young adult age / } \\
\text { traumatic history }\end{array}$ & - & - & $\begin{array}{l}3 \text { depressive } \\
\text { episodes in } \\
\text { young age }\end{array}$ & $\begin{array}{c}\text { recent } \\
\text { depressive } \\
\text { episode }\end{array}$ & $\begin{array}{c}\text { depressive } \\
\text { episode after a } \\
\text { death at the age } \\
\text { of } 18\end{array}$ & - \\
\hline context of present TGA & $\begin{array}{l}\text { conflict + several } \\
\text { death } \\
\text { announcements the } \\
\text { week before }\end{array}$ & $\begin{array}{l}\text { sea bath }+ \\
\text { context of } \\
\text { professional } \\
\text { overwork }\end{array}$ & $\begin{array}{c}\text { fibroscopy }+ \\
\text { extended } \\
\text { context of stress } \\
\text { (familial issue) }\end{array}$ & $\begin{array}{l}\text { death of a close } \\
\text { friend three } \\
\text { weeks before }\end{array}$ & gym & mowed the lawn & $\begin{array}{c}\text { professional } \\
\text { overwork }+ \\
\text { surgery of his } \\
\text { wife the previous } \\
\text { week }\end{array}$ \\
\hline precipitating event code & 7 & $4+7$ & $1+7$ & 7 & 2 & 2 & 7 \\
\hline self-estimation of health & 5 & 5 & - & 5 & 5 & 4 & 4.5 \\
\hline \multirow[t]{3}{*}{ precipitating event group } & PSY & PHYS & PSY & PSY & PHYS & PHYS & PSY \\
\hline & PA_09 & PA_10 & PA_12 & PA_13 & PA_14 & PA_15 & PA_16 \\
\hline & recovery & recovery & recovery & follow-up & follow-up & recovery & follow-up \\
\hline gender & $F$ & $\mathrm{~F}$ & $\mathrm{M}$ & $F$ & $\mathrm{M}$ & $\mathrm{M}$ & $\mathrm{F}$ \\
\hline age & 64 & 71 & 58 & 69 & 66 & 63 & 59 \\
\hline level of education & 17 & 14 & 14 & 8 & 17 & 9 & 14 \\
\hline Memory score (z-score)* & - & - & 0.45 & 0.45 & 0.29 & 0.32 & 0.45 \\
\hline number of TGA & 1 & 2 & 1 & 2 & 1 & 1 & 1 \\
\hline psychiatric history & - & $\begin{array}{l}\text { reactional } \\
\text { depressive } \\
\text { episode }\end{array}$ & - & traumatic history & - & - & $\begin{array}{c}\text { several } \\
\text { depressive } \\
\text { episodes }\end{array}$ \\
\hline context of present TGA & $\begin{array}{c}\text { Familial } \\
\text { argument }\end{array}$ & - & $\begin{array}{l}\text { very anxious } \\
\text { since the sister in } \\
\text { law's death the } \\
\text { previous week }\end{array}$ & $\begin{array}{l}\text { extended context } \\
\text { of stress (familial } \\
\text { and partner } \\
\text { issues) }\end{array}$ & $\begin{array}{c}\text { sexual } \\
\text { intercourse }\end{array}$ & familial issue & gym + shower \\
\hline precipitating event code & 1 & 8 & 7 & 7 & 5 & 1 & $2+4$ \\
\hline self-estimation of health & 4 & 4 & 3.5 & 3.5 & 4 & 5 & 4 \\
\hline precipitating event group & PSY & NONE & PSY & PSY & PHYS & PSY & PHYS \\
\hline
\end{tabular}




\begin{tabular}{|c|c|c|c|c|c|c|c|}
\hline & PA_17 & PA_18 & PA_19 & PA_20 & PA_21 & PA_23 & PA_24 \\
\hline & follow-up & follow-up & recovery & follow-up & acute & recovery & follow-up \\
\hline gender & $\mathrm{M}$ & $M$ & $M$ & $\mathrm{M}$ & $\mathrm{F}$ & $\mathrm{F}$ & $M$ \\
\hline age & 76 & 58 & 69 & 74 & 74 & 52 & 74 \\
\hline level of education & 11 & 14 & 17 & 20 & 12 & 12 & 9 \\
\hline Memory score (z-score)* & 0.29 & 0.45 & 0.29 & 0.29 & -14 & 0.32 & 0.45 \\
\hline number of TGA & 1 & 1 & 1 & 2 & 1 & 1 & 2 \\
\hline psychiatric history & - & $\begin{array}{c}\text { several } \\
\text { depressive } \\
\text { episodes }\end{array}$ & - & - & $\begin{array}{l}\text { recent } \\
\text { depressive } \\
\text { episode }\end{array}$ & - & - \\
\hline context of present TGA & $\begin{array}{c}\text { repaired, lifted and } \\
\text { carried alone a washing } \\
\text { machine }\end{array}$ & $\begin{array}{c}\text { maybe after a } \\
\text { shower? }\end{array}$ & gym & $\begin{array}{l}\text { played a public } \\
\text { concert }\end{array}$ & $\begin{array}{l}\text { gardening }+ \text { felt } \\
\text { unable to join } \\
\text { her husband to } \\
\text { visit their } \\
\text { daughter's grave }\end{array}$ & $\begin{array}{c}\text { car issue }+ \\
\text { context of } \\
\text { stressful moving }\end{array}$ & $\begin{array}{l}\text { very painful } \\
\text { constipation }\end{array}$ \\
\hline precipitating event code & 2 & $8(+4)$ & 2 & 1 & $2+1$ & $1+7$ & 3 \\
\hline self-estimation of health & 3 & 4 & 4.5 & 4.5 & - & 2 & 3 \\
\hline precipitating event group & PHYS & NONE & PHYS & PSY & PHYS & PSY & PHYS \\
\hline
\end{tabular}

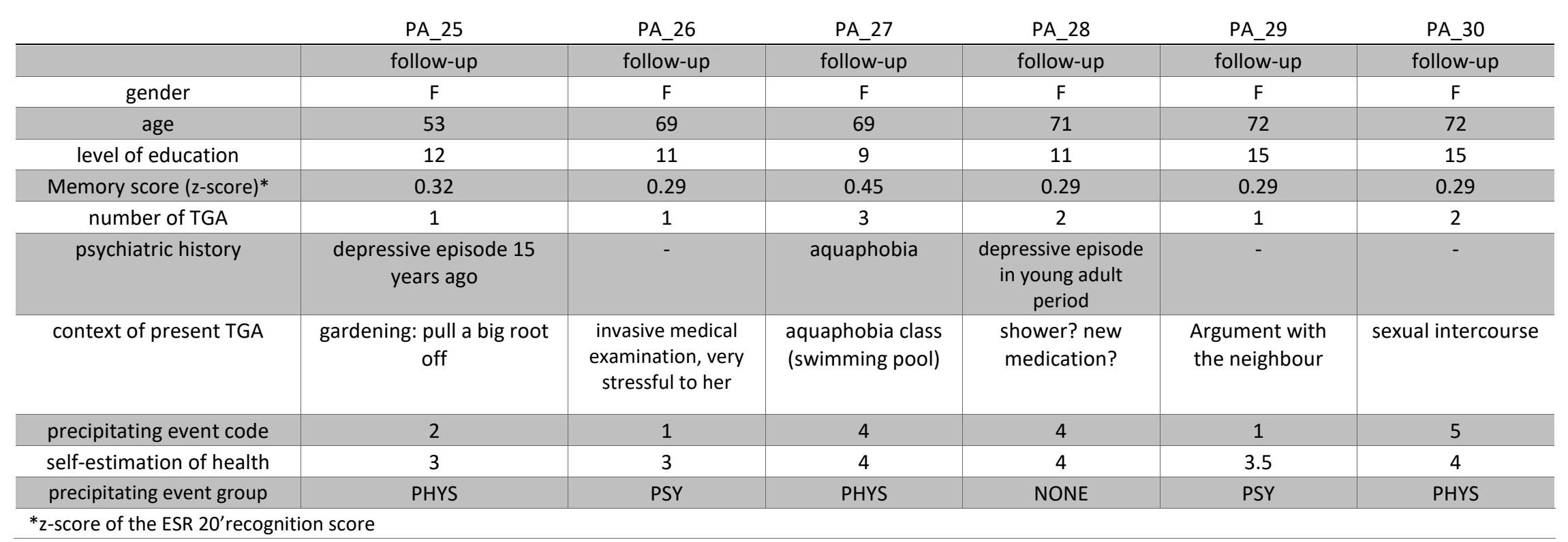




\section{Tables}

Table 1. Description of TGA patients and their matched control groups for the factor "TGA stage".

\begin{tabular}{cc|c|ccc} 
& Acute & Recovery & Follow-up & NC & $\begin{array}{c}\text { Kruskal-Wallis' } \\
\text { ANOVA }\end{array}$ \\
\hline N (F/M) & $6(6 / 0)$ & $8(3 / 5)$ & $13(8 / 5)$ & $11(6 / 5)$ & \\
Mean age & 65.67 & 61.63 & 67.85 & 61.91 & $\mathrm{H}=6.54$ \\
(SD) & $( \pm 9.89)$ & $( \pm 7.96)$ & $( \pm 7.01)$ & $( \pm 3.42)$ & $p=0.09$ \\
\hline Mean level of & 12 & 13.63 & 12.77 & 12.09 & $\mathrm{H}=1.39$ \\
education (SD) & $( \pm 3.46)$ & $( \pm 2.83)$ & $( \pm 3.47)$ & $( \pm 2.59)$ & $p=0.71$ \\
\hline Mean ESR & 9.3 & 15.83 & 15.92 & 15.89 & $\mathrm{H}=24.03$ \\
(encoding score)/16 & $( \pm 4.80)$ & $( \pm 0.41)$ & $( \pm 0.28)$ & $( \pm 0.33)$ & $p<.001$ \\
\hline Mean ESR & 1 & 6.3 & 9.23 & 8.22 & $\mathrm{H}=19.11$ \\
(free recall score)/16 & $( \pm 1.26)$ & $( \pm 1.03)$ & $( \pm 2.42)$ & $( \pm 2.33)$ & $p<.001$ \\
\hline Mean ESR & 9.5 & 16 & 16 & 16 & $\mathrm{H}=32.61$ \\
(recognition score)/16 & $( \pm 3.56)$ & $( \pm 0.00)$ & $( \pm 0.00)$ & $( \pm 0.00)$ & $p<.001$ \\
\hline Mean STAI-A (state & 46 & 32.17 & 23.45 & 26.11 & $\mathrm{H}=9.80$ \\
anxiety)/80 & $( \pm 19.73)$ & $( \pm 8.89)$ & $( \pm 4.18)$ & $( \pm 7.79)$ & $\mathrm{p}<.05$ \\
\hline Mean STAI-B (trait & 46 & 33.63 & 37.83 & 37.11 & $\mathrm{H}=3.87$ \\
anxiety) /80 & $( \pm 11.31)$ & $( \pm 5.88)$ & $( \pm 6.86)$ & $( \pm 9.36)$ & $p=0.28$ \\
\hline
\end{tabular}

Table 2. Description of TGA patients and their matched control groups for the factor "precipitating event group".

\begin{tabular}{|c|c|c|c|c|c|}
\hline & PSY & PHYS & NONE & $\mathrm{NC}$ & $\begin{array}{l}\text { Kruskal- } \\
\text { Wallis s } \\
\text { ANOVA }\end{array}$ \\
\hline $\mathbf{N}(\mathbf{F} / \mathbf{M})$ & $12(8 / 4)$ & $12(7 / 5)$ & $3(2 / 1)$ & $11(6 / 5)$ & \\
\hline Mean age (SD) & $\begin{array}{c}64.58 \\
( \pm 8.30)\end{array}$ & $\begin{array}{c}66.17 \\
( \pm 8.66)\end{array}$ & $\begin{array}{c}66.67 \\
( \pm 7.51)\end{array}$ & $\begin{array}{c}61.91 \\
( \pm 3.42)\end{array}$ & $\begin{array}{l}\mathrm{H}=3.46 \\
p=0.33\end{array}$ \\
\hline $\begin{array}{l}\text { Mean level of education } \\
\text { (SD) }\end{array}$ & $\begin{array}{c}12.42 \\
( \pm 3.82)\end{array}$ & $\begin{array}{c}13.25 \\
( \pm 2.99)\end{array}$ & $\begin{array}{c}13 \\
( \pm 1.73)\end{array}$ & $\begin{array}{c}12.09 \\
( \pm 2.59)\end{array}$ & $\begin{array}{l}\mathrm{H}=1.09 \\
p=0.78\end{array}$ \\
\hline $\begin{array}{l}\text { Mean ESR (encoding } \\
\text { score) } \\
\text { /16 }\end{array}$ & $\begin{array}{c}13.09 \\
( \pm 5.11)\end{array}$ & $\begin{array}{c}15.25 \\
( \pm 1.42)\end{array}$ & $\begin{array}{l}15.50 \\
( \pm 0.71)\end{array}$ & $\begin{array}{c}15.89 \\
( \pm 0.33)\end{array}$ & $\begin{array}{l}\mathrm{H}=2.44 \\
p=0.49\end{array}$ \\
\hline $\begin{array}{l}\text { Mean ESR (free-recall } \\
\text { score) } \\
/ 16\end{array}$ & $\begin{array}{c}5 \\
( \pm 3.52)\end{array}$ & $\begin{array}{c}7.50 \\
( \pm 3.80)\end{array}$ & $\begin{array}{c}9.50 \\
( \pm 4.95)\end{array}$ & $\begin{array}{c}8.22 \\
( \pm 2.33)\end{array}$ & $\begin{array}{l}\mathrm{H}=5.84 \\
p=0.12\end{array}$ \\
\hline $\begin{array}{l}\text { Mean ESR (recognition } \\
\text { score) } \\
\text { /16 }\end{array}$ & $\begin{array}{c}13.91 \\
( \pm 4.23)\end{array}$ & $\begin{array}{c}14.67 \\
( \pm 2.50)\end{array}$ & $\begin{array}{c}16 \\
( \pm 0.00)\end{array}$ & $\begin{array}{c}16 \\
( \pm 0.00)\end{array}$ & $\begin{array}{l}\mathrm{H}=3.38 \\
p=0.34\end{array}$ \\
\hline $\begin{array}{l}\text { STAI_A (state-anxiety) } \\
\text { /80 }\end{array}$ & $\begin{array}{r}28.38 \\
( \pm 9.29)\end{array}$ & $\begin{array}{c}30.90 \\
( \pm 16.58)\end{array}$ & $\begin{array}{c}33 \\
( \pm 8)\end{array}$ & $\begin{array}{c}26.11 \\
( \pm 7.79)\end{array}$ & $\begin{array}{l}\mathrm{H}=2.32 \\
p=0.51\end{array}$ \\
\hline $\begin{array}{l}\text { STAI_B (trait-anxiety) } \\
\text { /80 }\end{array}$ & $\begin{array}{c}38 \\
( \pm 6.45)\end{array}$ & $\begin{array}{c}35.89 \\
( \pm 9.44)\end{array}$ & $\begin{array}{c}37.33 \\
( \pm 4.51)\end{array}$ & $\begin{array}{c}31.11 \\
( \pm 9.36)\end{array}$ & $\begin{array}{l}\mathrm{H}=0.47 \\
p=0.93\end{array}$ \\
\hline
\end{tabular}


Table 3. Repartition of TGA patients according to TGA stages (columns) and precipitating event group (lines).

\begin{tabular}{c|c|c|c|} 
& $\begin{array}{c}\text { Periacute patients } \\
\text { (acute/recovery) }\end{array}$ & $\begin{array}{c}\text { Follow-up } \\
\text { patients }\end{array}$ & TOTAL \\
\hline PSY & $8(3 / 5)$ & 4 & 12 \\
\hline PHYS & $5(3 / 2)$ & 7 & 12 \\
\hline TOTAL & $13(6 / 7)$ & 11 & 24 \\
\hline
\end{tabular}

Pearson's chi-square test confirmed the independence between the factors "TGA phase" and "Precipitating event group" $\left(\mathrm{Chi}^{2}=1.51\right.$; $\mathrm{df}=1 ; p=0.22$ ).

\section{Figures}

Figure 1

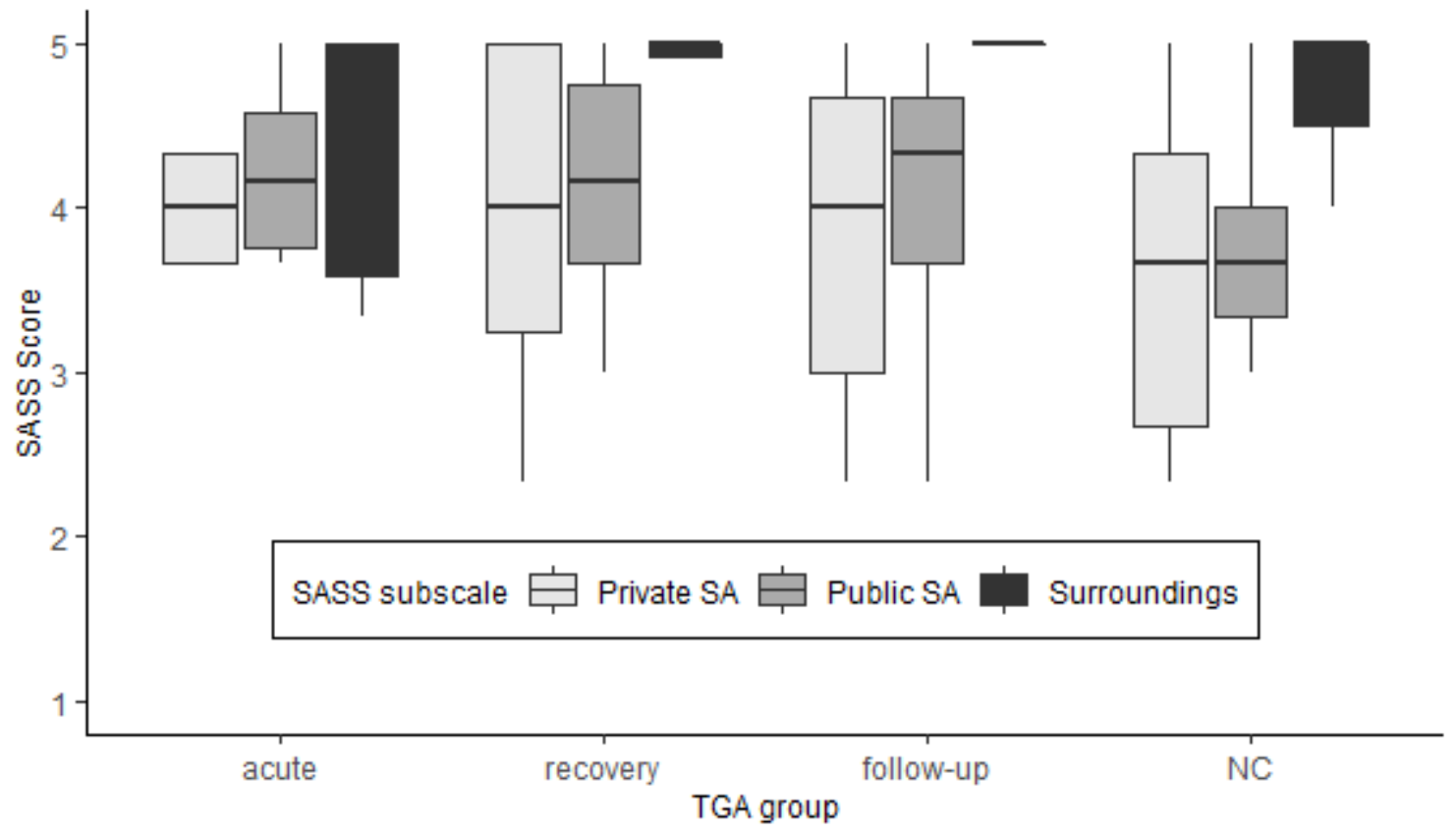

Figure 2 


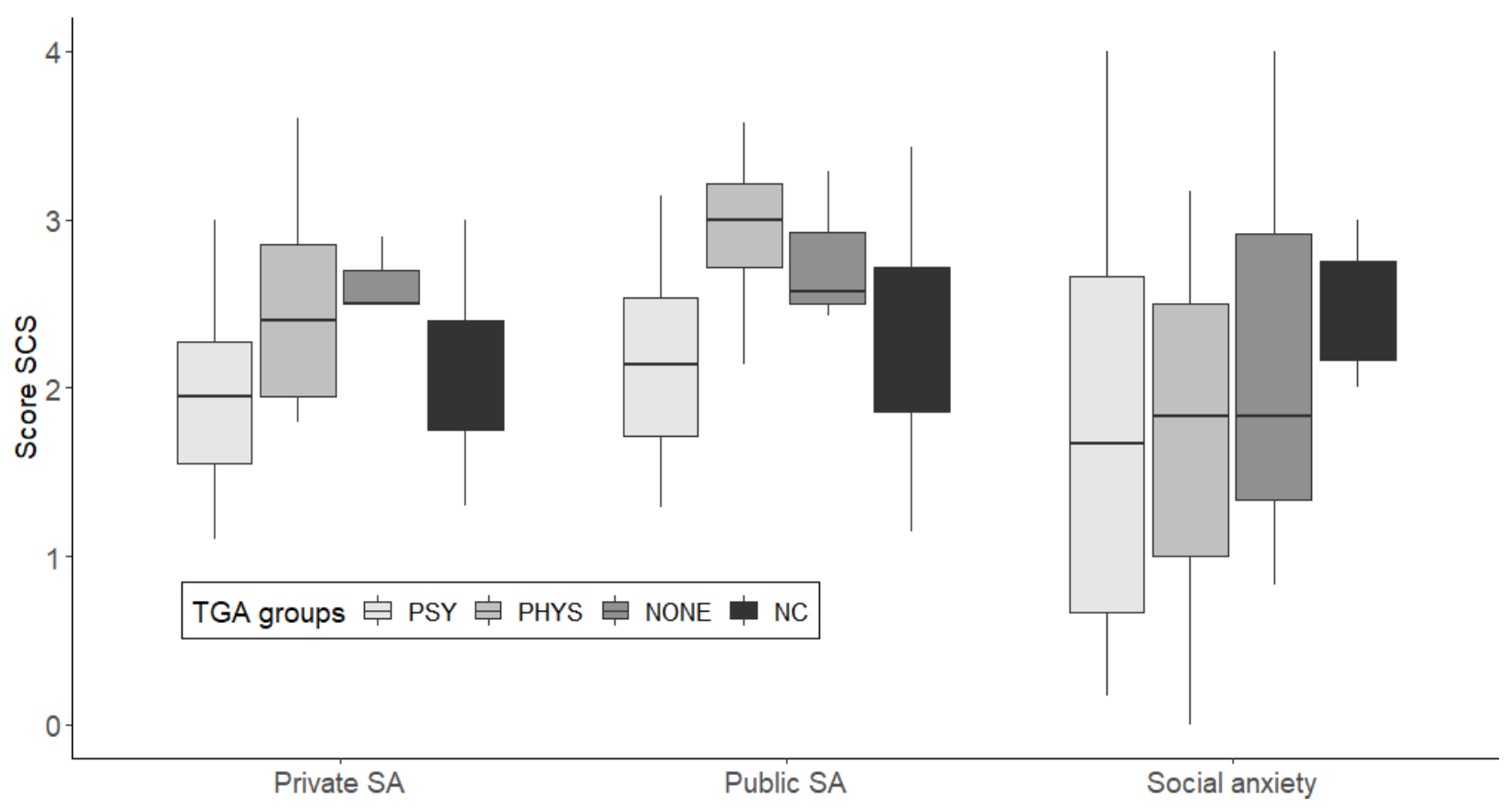




\section{Figure captions}

Figure 1. Intragroup analysis for SASS scale. Boxplots were constructed from median and $1^{\text {rst }}$ and $3^{\text {rd }}$ quartile scores. Bars corresponds to $1.5 * I Q R$. Friedman ANOVAs are significant for recovery group $\left(A N O V A C h i^{2}=\right.$ 6,87; $p<.05)$, follow-up group (ANOVA Chi $\left.{ }^{2}=12,88 ; p<.01\right)$, trend for NC group (ANOVA Chi ${ }^{2}=4,43 ; p=0.11$ ), but not for the acute group (ANOVA Chi ${ }^{2}=1.37 ; p=0.50$ ). Post-hoc analysis showed that surroundings scale was superior than private and public (self-scales) SA in recovery group (private/surroundings : Wilcoxon's $Z=1.89, p=.05, \quad r=0.54$; public/surroundings: Wilcoxon's $Z=2.20, p<.05, r=0.64)$, follow-up group (private/surroundings : Wilcoxon's $Z=2.80, p<.01, r=0.63$; public/surroundings: Wilcoxon's $Z=2.62, p<.01$, $r=0.56$ ) and NC group (private/surroundings : Wilcoxon's $Z=2.14, p<.05, r=0.48$; public/surroundings: Wilcoxon's $Z=2.45, p<.05, r=0.52$ ). There was no difference between private and public $S A$ scales in none group (all $p>0.22$ ).

Figure 2. Comparison of dispositional Self-consciousness scale scores in TGA groups according to the kind of precipitating event (PSY, PHYS or NONE) and NC group. Boxplots were constructed from median and $1^{\text {rst }}$ and $3^{\text {rd }}$ quartile scores. Bars correspond to $1.5^{*} I Q R$. Differences are significant between PHYS and PSY groups $(p<.05)$ and between PHYS and NC groups $(p<.05)$ in "Public SA" subscores. 